Formatif: Jurnal Ilmiah Pendidikan MIPA

Vol. 9, No. 4, December 2019, pp. 305-314

p-ISSN: 2088-351X

e-ISSN: 2502-5457

DOI: http://dx.doi.org/10.30998/formatif.v9i4.3530

\title{
The Influence of Android-Based Multimedia Modules on Static Fluid Material on Understanding The Physics Concepts of High School Students
}

\author{
Pengaruh Modul Multimedia Berbasis Android pada Materi Fluida Statis terhadap \\ Pemahaman Konsep Fisika Siswa SMA
}

\author{
Winarti Purnama Sari (*) \\ Universitas Lampung \\ I Dewa Putu Nyeneng \\ Universitas Lampung \\ Ismu Wahyudi \\ Universitas Lampung
}

Received: March 24, 2019

Revised: December 02, 2019

Accepted: December 03, 2019

\begin{abstract}
Students 'ability to understand the concept of physics is still weak, so it is necessary to use learning resources that are able to improve students' conceptual understanding. This study aims to determine the effect of android-based multimedia modules on understanding the physics concepts of high school students in static fluid material. The sample of this study was students of class XI MIA 1 and XI MIA 2 of SMA 1 Raman Utara. This study was conducted using the type of pretest-posttest control group design. The data obtained were then tested by $\mathrm{N}$-gain analysis, normality test, homogeneity test, independent sample t-test, and effect size test. Data from the study were collected using pretest and posttest with conceptual understanding indicators. The results show that there is an influence of the use of multimedia modules on understanding students' concepts in static fluid material. The results of the study obtained an average $\mathrm{N}$-gain score of the experimental class and control class of 0.54 and 0.31 with the medium category and the effect size value of 2.8 with a large category. The results of different tests using independent sample t-test $<0.05$ showed that there were significant differences in students' ability to understand concepts using using multimedia-based android modules and students using print modules.
\end{abstract}

Keywords: static fluid, android-based multimedia modules, understanding concepts.

(*) Corresponding Author:

winartipurnamasari9@gmail.com - +6282182862678

How to Cite: Sari, W.P., Nyeneng, I.D.P., \& Wahyudi, I. (2019). The influence of android-based multimedia modules on static fluid material on understanding the physics concepts of high school students. Formatif: Jurnal Ilmiah Pendidikan MIPA, 9 (4): 305-314. http://dx.doi.org/10.30998/formatif.v9i4.3530

\section{PENDAHULUAN}

Pembelajaran abad 21 merupakan pembelajaran yang mempersiapkan generasi abad 21 di mana perkembangan teknologi semakin cepat dan memiliki pengaruh terhadap proses pembelajaran. Abad 21 disebut juga era global, di mana siswa harus menguasai kecakapan tertentu. Siswa dituntut untuk mampu mengembangkan kecakapan dalam 
Formatif: Jurnal Ilmiah Pendidikan MIPA

Vol. 9, No. 4, December 2019, pp. 305-314

p-ISSN: 2088-351X

e-ISSN: $2502-5457$

DOI: http://dx.doi.org/10.30998/formatif.v9i4.3530

menguasai TIK, sehingga siswa memiliki kemampuan menggunakan teknologi pada proses pembelajaran yang bertujuan untuk mencapai kecakapan berpikir siswa. Pembelajaran abad 21 menekankan keterampilan-keterampilan yang harus dikuasai seperti critical thinking dan problem solving, creativity dan innovation, communication, serta collaboration.

Tujuan pendidikan Indonesia sesuai dengan salah satu prioritas pendidikan abad 21 yaitu menurut Permendiknas No 22 Tahun 2006, salah satu tujuan mempelajari matematika agar siswa memiliki kemampuan memecahkan masalah. Hasil survei Programme for Internasional Student Asessment (PISA) menunjukkan bahwa kemampuan siswa di Indonesia dalam memecahkan masalah masih tergolong kurang. Pada hasil survei PISA tahun 2015 untuk sains, Indonesia hanya memperoleh skor ratarata 403 jika dibandingkan dengan rata-rata skor Organisation for Economic Cooperation and Development (OECD) yaitu sebesar 494. Rendahnya kemampuan siswa dalam memecahkan suatu masalah menunjukkan perlunya suatu pembelajaran yang dirancang agar siswa terbiasa menyelesaikan soal pemecahan masalah.

Kemampuan siswa dalam menyelesaikan soal pemecahan masalah bergantung pada pemahaman konsep siswa. Siswa dapat memiliki konsep yang baik apabila pembelajaran yang diterima lebih bermakna. Pada mata pelajaran fisika umumnya hanya menekankan pada soal-soal yang menggunakan rumus perhitungan. Akibatnya konsep yang diperoleh siswa melalui pembelajaran tidak begitu kuat, sehingga ketika siswa dihadapkan dengan soal pemecahan masalah siswa merasa kesulitan. Kemampuan siswa dalam memahami konsep merupakan kemampuan menjelaskan fenomena yang diamati, mencontohkan materi yang dipelajari terhadap kehidupan sehari-hari, menyimpulkan percobaan yang telah dilakukan, dan membandingkan antara hasil percobaan dengan teori. Siswa tidak hanya mampu mencontohkan, menjelaskan, menyimpulkan, serta membandingkan, namun siswa mampu memecahkan masalah yang berkenaan dengan konsep tersebut (Hamalik, 2008:166). Pemecahan masalah dapat dilakukan dengan melakukan percobaan yang sederhana. Siswa dapat membentuk kelompok untuk melakukan percobaan, sehingga kegiatan pembelajaran dapat berjalan efektif. Pembelajaran yang dilakukan guru berdasarkan tuntutan abad 21 guru harus merancang pembelajaran yang inovatif dan kreatif, salah satunya dengan menggunakan modul multimedia berbasis Android.

Modul multimedia berbasis Android dapat menjadi alternatif sebagai penunjang proses pembelajaran agar lebih fleksibilitas dalam kegiatan belajar mengajar. Pembelajaran dengan menggunakan modul multimedia berbasis Android memiliki beberapa kelebihan dibandingkan dengan pembelajaran lainnya yaitu dapat diakses di manapun. Modul multimedia berbasis Android ini memanfaatkan teknologi komunikasi bergerak, sehingga dalam pembelajaran siswa akan disuguhkan gambar yang terlihat nyata. Hasil penelitian Esra dan Berna (2010) menunjukkan bahwa multimedia dapat membantu dalam memahami matematika yang lebih bermakna, untuk konseptualisasi matematika, dan memahami pentingnya matematika. Pembelajaran dengan menggunakan modul multimedia berbasis Android siswa dengan mudah mengaitkan antara teori dengan fenomena pada kehidupan sehari-hari, sehingga siswa dapat memahami konsep pembelajaran dengan baik. Pemahaman siswa terhadap konsep pembelajaran dipengaruhi oleh model pembelajaran yang diterapkan guru. Penerapan modul multimedia dalam pembelajaran lebih efektif apabila guru mempertimbangkan pengalokasian waktu setiap langkah-langkah pembelajaran.

Penerapan model pembelajaran harus sesuai dengan tuntutan abad 21 yang melibatkan siswa aktif dalam proses pembelajaran. Salah satu model pembelajaran yang dapat diterapkan adalah model pembelajaran inkuiri terbimbing. Model pembelajaran 
inkuiri terbimbing yaitu pembelajaran yang dalam pelaksanaannya melibatkan siswa dalam menemukan suatu konsep materi pembelajaran. Pembelajaran menggunakan model inkuiri terbimbing akan melibatkan siswa dalam pembelajaran, sehingga siswa menjadi lebih aktif dalam menyelesaikan setiap masalah. Penerapan model pembelajaran inkuiri terbimbing dengan modul multimedia berbasis Android ini menjadi perangkat pembelajaran yang efektif diterapkan, sehingga siswa dapat meningkatkan kemampuan dalam memahami konsep dengan mudah.

Peningkatan pemahaman siswa terhadap konsep fisika perlu menggunakan sumber belajar yang menyajikan fenomena pada kehidupan sehari-hari yang terlihat nyata. Penggunaan sumber belajar yang berbeda dari yang diterapkan guru contohnya pada materi fluida statis, dapat menggunakan modul multimedia berbasis Android dalam pembelajaran di sekolah. Fluida statis adalah salah satu materi yang dianggap sulit karena berkaitan dengan fenomena dalam kehidupan sehari-hari. Melihat permasalahan di atas peneliti manfaatkan modul multimedia berbasis Android pada materi fluida statis untuk meningkatkan pemahaman konsep fisika siswa SMA.

\section{METODE}

Penelitian ini merupakan penelitian dengan metode quassy eksprimental dengan menggunakan desain penelitian Pretest-Posttest Control Group Design, yaitu satu kelompok kelas diberi treatment, kemudian satu kelompok lain dijadikan sebagai kelompok kelas kontrol. Kelas yang diberikan treatment yaitu kelas eksperimen dengan pembelajaran menggunakan modul multimedia berbasis Android dan kelas kontrol yang menerapkan modul cetak pada pembelajaran. Sampel penelitian ini yaitu kelas XI MIA 2 sebagai kelas eksperimen dan kelas XI MIA 1 sebagai kelas kontrol. Penelitian ini memiliki tiga variabel, yaitu modul multimedia berbasis Android sebagai variabel bebas, pemahaman konsep sebagai variabel terikat, dan inkuiri terbimbing sebagai variabel moderator. Instrumen yang digunakan pada penelitian ini adalah instrumen yang telah diuji validitas dan reliabilitasnya. Instrumen tersebut digunakan untuk mengukur pemahaman konsep fisika siswa pada materi fluida statis. Data penelitian yang didapatkan berupa data kuantitatif yaitu nilai pretest dan posttest. Data yang telah diperoleh kemudian dianalisis untuk mencari nilai $\mathrm{N}$-gain, data $\mathrm{N}$-gain tersebut diuji normalitas, uji homogenitas, uji independent sample t-test, dan uji effect size. Uji independent sample t-test digunakan untuk mengetahui perbedaan pemahaman konsep kelas eksperimen dan kelas kontrol. Uji effect size digunakan untuk mengetahui besar pengaruh modul multimedia berbasis Android terhadap pemahaman konsep fisika siswa SMA pada materi fluida statis.

\section{HASIL DAN PEMBAHASAN}

\section{Hasil}

Penelitian pengaruh modul multimedia berbasis Android ini telah dilakukan di SMAN 1 Raman Utara pada 30 Januari sampai 8 Februari 2019. Proses pembelajaran berlangsung selama empat kali tatap muka dengan alokasi waktu delapan jam pelajaran. Setiap jam pembelajaran terdiri atas 45 menit. Kelas eksperimen menerapkan pembelajaran menggunakan modul multimedia berbasis Android sedangkan pada kelas kontrol pembelajaran hanya menggunakan modul cetak. Data nilai rata-rata pretest dan 
Formatif: Jurnal Ilmiah Pendidikan MIPA

Vol. 9, No. 4, December 2019, pp. 305-314

p-ISSN: 2088-351X

e-ISSN: 2502-5457

DOI: http://dx.doi.org/10.30998/formatif.v9i4.3530

posttest pemahaman konsep siswa dapat dilihat pada tabel 1. Pada tabel tersebut dapat dilihat nilai rata-rata siswa kelas eksperimen dan kelas kontrol.

Tabel 1. Data Nilai Pretest dan Posttest

\begin{tabular}{cccccc}
\hline \multirow{2}{*}{ No } & \multirow{2}{*}{ Nilai } & \multicolumn{2}{c}{ Kelas Eksperimen } & \multicolumn{2}{c}{ Kelas Kontrol } \\
& & Pretest & Posttest & Pretest & Posttest \\
\hline 1 & Terendah & 36,67 & 83,33 & 33,33 & 46,66 \\
2 & Tertinggi & 56,67 & 63,33 & 53,33 & 73,33 \\
3 & Rata-rata & 46,96 & 75,65 & 43,94 & 61,21 \\
\hline
\end{tabular}

Tabel tersebut memuat nilai rata-rata pretest dan posttest pemahaman konsep fisika siswa pada kelas eksperimen dan kelas kontrol. Rata-rata nilai pretest kelas eksperimen lebih besar dari rata-rata nilai kelas kontrol. Rata-rata nilai pretest pemahaman konsep kelas eksperimen hanya mencapai 46,96 poin setelah diberikan perlakuan pembelajaran menggunakan modul multimedia berbasis Android terjadi peningkatan sebesar 28,69 poin sehingga rata-rata posttest pemahaman konsep siswa menjadi 75,65 poin. Rata-rata pretest pemahaman konsep kelas kontrol hanya mencapai 43,94 poin setelah guru memberikan pembelajaran menggunakan modul cetak terjadi peningkatan nilai postest sebesar 17,27 poin sehingga rata-rata posttest pemahaman konsep menjadi 61,21 poin. Perbedaan peningkatan posttest ini berbeda dikarenakan pada kelas eksperimen menggunakan sumber belajar yang berbeda dengan kelas kontrol.

Data nilai pretest dan posttest digunakan untuk mencari gain kelas eksperimen dan kelas kontrol. Gain yang dianalisis merupakan peningkatan pemahaman konsep pada setiap indikator pada materi fluida statis. Peningkatan kemampuan pemahaman konsep siswa dapat dilihat dari selisih antara hasil tes setelah diberi perlakuan dengan hasil tes sebelum diberi perlakuan. Indikator pemahaman konsep yang diukur oleh peneliti berupa menjelaskan, mencontohkan, menyimpulkan, dan membandingkan. Hasil analisis gain kelas eksperimen dan kelas kontrol setiap indikator dapat dilihat pada tabel 2 dan tabel 3.

Tabel 2. Data Hasil Gain Indikator Pemahaman Konsep Kelas Eksperimen

\begin{tabular}{lllllllll}
\hline \multirow{2}{*}{ Nilai } & \multicolumn{7}{c}{ Kelas Eksperimen } \\
\cline { 2 - 9 } & Menjelaskan & \multicolumn{2}{c}{ Mencontohkan } & \multicolumn{2}{c}{ Menyimpulkan } & \multicolumn{2}{c}{ Membandingkan } \\
& Pre & Post & Pre & Post & Pre & Post & Pre & Post \\
\hline $\begin{array}{l}\text { Nilai } \\
\text { Tertinggi }\end{array}$ & 4 & 6 & 6 & 8 & 6 & 9 & 4 & 6 \\
$\begin{array}{l}\text { Nilai } \\
\text { Terendah }\end{array}$ & 1 & 4 & 2 & 4 & 3 & 4 & 1 & 2 \\
$\begin{array}{l}\text { Rata-rata } \\
\text { Nilai }\end{array}$ & 8,26 & 14,64 & 14,64 & 21,45 & 15,07 & 24,40 & 8,99 & 15,36 \\
\hline
\end{tabular}


Formatif: Jurnal Ilmiah Pendidikan MIPA

Vol. 9, No. 4, December 2019, pp. 305-314

p-ISSN: 2088-351X

e-ISSN: 2502-5457

DOI: http://dx.doi.org/10.30998/formatif.v9i4.3530

Tabel 3. Data Hasil Gain Indikator Pemahaman Konsep Kelas Kontrol

\begin{tabular}{lllllllll}
\hline \multirow{2}{*}{ Nilai } & \multicolumn{7}{c}{ Kelas Kontrol } \\
\cline { 2 - 9 } & \multicolumn{2}{c}{ Menjelaskan } & \multicolumn{2}{c}{ Mencontohkan } & \multicolumn{2}{c}{ Menyimpulkan } & \multicolumn{2}{c}{ Membandingkan } \\
& Pre & Post & Pre & Post & Pre & Post & Pre & Post \\
\hline $\begin{array}{l}\text { Nilai } \\
\text { Tertinggi }\end{array}$ & 4 & 5 & 6 & 7 & 6 & 7 & 4 & 5 \\
$\begin{array}{l}\text { Nilai } \\
\text { Terendah }\end{array}$ & 1 & 2 & 2 & 2 & 2 & 3 & 1 & 0 \\
$\begin{array}{l}\text { Rata-rata } \\
\text { Nilai }\end{array}$ & 8,18 & 13,03 & 13,33 & 16,97 & 13,79 & 19,24 & 8,64 & 11,97 \\
\hline
\end{tabular}

Kelas eksperimen dan kelas kontrol pada setiap indikator mengalami peningkatan dari sebelum pembelajaran hingga diterapkan sesudah pembelajaran. Pembelajaran pada kelas eksperimen yang menerapkan modul multimedia berbasis Android mengalami peningkatan yang cukup tinggi dibandingkan kelas kontrol yang menerapkan modul cetak. Peningkatan pemahaman konsep dapat dilihat berdasarkan $\mathrm{N}$-gain keseluruhan kelas eksperimen dan kelas kontrol. Berikut ini $\mathrm{N}$-gain kelas eksperimen dan kelas kontrol dapat dilihat pada tabel 4.

Tabel 4. Data Hasil N-gain Pemahaman Konsep

\begin{tabular}{lcc}
\hline \multicolumn{1}{c}{ Perolehan Skor } & Kelas Eksperimen & Kelas Kontrol \\
\hline Gain Tertinggi & 0,67 & 0,50 \\
Gain Terendah & 0,42 & 0,06 \\
Rata-rata Gain & 28,70 & 17,27 \\
Kenaikan Skor Rata-rata & $29 \%$ & $17 \%$ \\
Rata-rata $N$-gain & 0,54 & 0,31 \\
Kategori & Sedang & Sedang \\
\hline
\end{tabular}

Hasil $N$-gain pemahaman konsep fisika kelas eksperimen maupun kelas kontrol berkategori sedang, namun rata-rata $N$-gain yang berbeda. Kelas eksperimen memiliki rata-rata $N$-gain sebesar 0,54 dan kelas kontrol sebesar 0,31 , sehingga peningkatan pemahaman konsep kelas eksperimen lebih tinggi dari peningkatan pemahaman konsep kelas kontrol. Nilai $\mathrm{N}$-gain yang diperoleh digunakan untuk menguji normalitas data kelas eksperimen dan kelas kontrol dengan menggunakan SPSS metode KolmogrovSmirnov. Hasil uji normalitas dapat dilihat pada tabel 5.

Tabel 5. Hasil Uji Normalitas

\begin{tabular}{lcc}
\hline \multicolumn{1}{c}{ Hasil } & Asymp. Sig. (2-tailed) & Kesimpulan \\
\hline Kelas Eksperimen & 0,762 & $\mathrm{H}_{0}$ diterima \\
Kelas Kontrol & 0,779 & $\mathrm{H}_{0}$ diterima \\
\hline
\end{tabular}

Hasil uji normalitas yang telah dilakukan pada kelas eksperimen dan kelas kontrol lebih dari 0,05 , hal ini menunjukkan bahwa sampel penelitian yang digunakan berdistribusi normal. Peneliti melakukan uji homogenitas untuk mengetahui apakah varian data sama atau tidak. Uji homogenitas ini dilakukan sebagai prasyarat dalam analisis independent sample t-test dengan menggunakan homogeneity of variances pada one way anova. 
Formatif: Jurnal Ilmiah Pendidikan MIPA

Vol. 9, No. 4, December 2019, pp. 305-314

p-ISSN: 2088-351X

e-ISSN: 2502-5457

DOI: http://dx.doi.org/10.30998/formatif.v9i4.3530

Variabel yang diuji homogenitasnya adalah $N$-gain rata-rata dari masing-masing kelas. Hasil uji homogenitas dapat dilihat pada tabel 6.

Tabel 6. Hasil Uji Homogenitas

\begin{tabular}{cccc}
\hline Levene Statistic & $d f 1$ & $d f 2$ & Sig. \\
\hline 0,487 & 1 & 43 & 0,489 \\
\hline
\end{tabular}

Uji homegenitas yang telah dilakukan dengan nilai signifikan lebih dari 0,05 maka dapat disimpulkan bahwa kedua kelompok data mempunyai varian yang sama atau homogen. Uji homogenitas yang telah dilakukan sebagai prasyarat untuk melakukan uji independent sample t-test untuk mengetahui ada tidaknya perbedaan rata-rata pemahaman konsep siswa sebelum dan sesudah dilakukan pembelajaran pada masing-masing kelas eksperimen dan kelas kontrol. Uji independent sample t-test yang dilakukan dengan menggunakan rata-rata $N$-gain dari masing-masing kelas eksperimen dan kelas kontrol. Hasil uji independent sample t-test yang telah dilakukan dapat dilihat pada tabel 7.

Tabel 7. Hasil Uji Independent Sample T-test

\begin{tabular}{|c|c|c|c|}
\hline & & \multicolumn{2}{|c|}{ Gain } \\
\hline & & $\begin{array}{c}\text { Equal Variances } \\
\text { Assumed }\end{array}$ & $\begin{array}{c}\text { Equal Variances Not } \\
\text { Assumed }\end{array}$ \\
\hline & $\mathrm{T}$ & 9,544 & 9,504 \\
\hline $\begin{array}{c}t \text {-test } \\
\text { aty }\end{array}$ & Df & 43,000 & 40,876 \\
\hline $\begin{array}{c}\text { equatity } \\
\text { Means }\end{array}$ & $\begin{array}{l}\text { Sig. }(2- \\
\text { Tailed) }\end{array}$ & 0,000 & 0,000 \\
\hline
\end{tabular}

Penelitian ini disajikan dengan sampel 23 siswa kelas eksperimen dan 22 siswa kelas kontrol yang telah diuji menggunakan independent sample t-test menghasilkan nilai kurang dari 0,05 , menunjukkan terdapat perbedaan yang signifikan antara pemahaman konsep siswa dengan menggunakan modul multimedia berbasis Android dan siswa menggunakan modul cetak. Pengaruh modul multimedia berbasis Android terhadap pemahaman konsep siswa diukur menggunakan uji effect size. Uji effect size ini dilakukan dengan menggunakan kalkulator cohen's $d$. Hasil effect size $\mathrm{r}$ pemahaman konsep yang diperoleh dari perhitungan yaitu sebesar 2,8, sehingga dapat dikatakan terdapat pengaruh yang cukup tinggi dalam menerapkan modul multimedia berbasis Android terhadap peningkatan pemahaman konsep siswa.

\section{Pembahasan}

Penelitian ini dilakukan untuk mengetahui pengaruh modul multimedia berbasis Android terhadap pemahaman konsep fisika siswa pada materi fluida statis. Penelitian yang dilakukan dengan cara memberikan soal pretest dan posttest pemahaman konsep dan aktivitas menggunakan langkah pembelajaran inkuiri terbimbing. Pembelajaran pada kelas eksperimen menggunakan modul multimedia berbasis Android yang menyajikan materi tidak hanya berupa teori namun suara, teks, dan video sedangkan pada kelas kontrol menggunakan modul cetak yang hanya menyajikan teks. Siswa di kelas eksperimen sangat tertarik dalam kegiatan pembelajaran. Hal ini dikarenakan mereka belum pernah menggunakan media pembelajaran seperti modul multimedia berbasis Android yang di dalamnya terdapat video, teks, dan suara. Hal ini sependapat dengan Suyanto (2005: 21) yang mengatakan bahwa dengan menerapkan beberapa kombinasi 
Formatif: Jurnal Ilmiah Pendidikan MIPA

Vol. 9, No. 4, December 2019, pp. 305-314

p-ISSN: 2088-351X

e-ISSN: $2502-5457$

DOI: http://dx.doi.org/10.30998/formatif.v9i4.3530

dalam multimedia baik suara, animasi, video, teks, dan gambar, maka dapat menarik fokus siswa dalam pembelajaran.

Proses pembelajaran yang disampaikan dengan mengamati video fenomena pada kehidupan sehari-hari dilanjutkan dengan melakukan percobaan dan siswa mengemukakan hasil percobaannya di depan kelas. Pembelajaran tersebut dapat melatih pemahaman siswa dalam mengingat pembelajaran yang telah dilakukan, sehingga pemahaman siswa akan meningkat. Hal ini sejalan dengan Syamsidar (2018) yang mengungkapkan bahwa tingkat ingatan hasil pembelajaran sebesar 90\% dengan cara simulasi dan kerja nyata. Pembelajaran di kelas menuntut guru untuk kreatif dengan memanfaatkan media secara efektif dan melakukan percobaan langsung akan memperkuat ingatan siswa.

Modul multimedia berbasis Android memuat soal-soal interaktif agar siswa dapat melatih kemampuannya secara mandiri. Soal interaktif yang telah tersedia memudahkan siswa dalam memecahkan masalah dikarenakan apabila dalam pengerjaan soal tersebut salah dapat dikerjakan kembali dengan memanfaatkan media lain seperti ruang guru, tempat bimbel, dan internet. Hal ini sesuai dengan Parmin (2012) yang mengatakan bahwa penerapan modul interaktif sangat efektif diterapkan dalam pembelajaran dan dapat memecahkan masalah dengan leluasa di rumah. Sebaliknya, pada kelas kontrol yang menerapkan modul cetak tidak tersedia soal interaktif yang masih mengandalkan kontekstual.

Langkah kelima pada proses pembelajaran inkuiri terbimbing yaitu mengumpulkan data dan menganalisis suatu percobaan. Peneliti memberikan kesempatan kepada siswa untuk berdiskusi menganalisis data yang telah diperoleh bersama kelompok masing-masing untuk menemukan jawaban. Setiap siswa dapat menyampaikan pendapat dengan anggota kelompok sesuai kemampuannya. Hal ini sependapat dengan Suryaningsih (2010: 31) yang menyebutkan bahwa modul interaktif yang diterapkan menggunakan inkuiri terbimbing akan meningkatkan motivasi siswa karena dalam proses pembelajaran siswa belajar sesuai dengan kemampuannya. Proses pembelajaran menggunakan inkuiri terbimbing akan lebih membantu siswa dalam memecahkan masalah yang berkaitan dengan kehidupan sehari-hari. Penyajian masalah yang ada dapat berpengaruh terhadap pemahaman konsep siswa. Hal ini sejalan dengan Sakdiyah, dkk. (2018) bahwa pembelajaran inkuiri terbimbing mengarahkan siswa untuk berpartisipasi aktif agar terlatih dalam memecahkan masalah dalam pengambilan keputusan. Penerapan pembelajaran menggunakan inkuiri terbimbing dapat menanamkan konsep pada siswa, dikarenakan siswa belajar tidak hanya dari teori melainkan menyelesaikan suatu persoalan melalui percobaan.

Kegiatan membuat kesimpulan pada akhir pembelajaran dilakukan dengan cara masing-masing kelompok mempresentasikan hasil yang telah diperoleh di depan kelas. Penyampaian kesimpulan di depan kelas dapat melatih kemampuan berkomunikasi di depan kelas sesuai dengan kriteria tuntutan abad 21 yang harus dikuasai. Setiap siswa terampil mengemukakan pendapat dan menjawab setiap pertanyaan yang ditanyakan kelompok lain. Hal ini sesuai dengan pendapat Hamalik (2008: 166) bahwa setiap siswa yang memahami konsep akan mampu menjawab pertanyaan-pertanyaan yang diberikan tidak hanya berupa contoh, ciri, membandingkan, namun menjawab semua pertanyaan yang berkaitan dengan konsep tersebut. Kegiatan pembelajaran yang menarik membuat siswa tertantang dalam memecahkan suatu masalah, sehingga modul multimedia berbasis Android dapat dijadikan alternatif pembelajaran yang dapat diterapkan oleh guru untuk meningkatkan pemahaman konsep siswa. 
Hasil penelitian pembelajaran menggunakan modul multimedia berbasis Android pada materi fluida statis dapat meningkatkan pemahaman konsep fisika siswa SMA. Hal ini dibuktikan dengan rata-rata nilai $\mathrm{N}$-gain kelas eksperimen lebih besar dari pada kelas kontrol sebesar 0,54 dan 0,31. Uji beda yang telah dilakukan menggunakan independent sample t-test menunjukkan nilai kurang dari 0,05 , hal ini menunjukkan bahwa terdapat perbedaan yang signifikan antara kelas eksperimen yang menggunakan modul multimedia berbasis Android dengan kelas kontrol yang menggunakan modul cetak. Besarnya pengaruh modul multimedia berbasis Android cukup tinggi dengan nilai effect size sebesar 2,8 dengan kriteria besar.

\section{DAFTAR PUSTAKA}

Anderson, L., W., \& Krathwohl, D., R. (2001). A Taxonomy for Learning, Teaching, and Assesing: A Revision of Bloom's, Taxonomy of Educational Objectives. London: Longman.

Arikunto, S. (2012). Dasar-dasar Evaluasi Pendidikan. Jakarta: Bumi Aksara.

Cohen, J. (1994). Statistical Power Analysis For The Behavioral Science (Second Edition) Hillsdale. N.J: Erlbaum.

Ersa \& Berna. (2010). Prospective mathematics teachers' views about using flash animations in mathematics lessons. Internasional Journal of Education and Pedagogical Sciences, 4 (3), 154-166.

Hakim, A., Liliasari., Asep K., Yana M. S., \& Iqbal M. (2012). Student concept understanding of natural products chemistry in primary and secondary metabolies using the data collecting technique of modified CRI. International Journal of Education Sciences, 4 (3), 1-8.

Hamalik, O. (2008). Perencanaan Pengajaran Berdasarkan Pendekatan Sistem. Jakarta: Bumi Aksara.

Handaka, A., Sukarmin, \& Sunarno, W. (2018). Pembelajaran fisika melalui kontruktivisme menggunakan metode inkuiri terbimbing dan inkuiri bebas termodifikasi ditinjau dari motivasi berprestasi dan sikap ilmiah. Jurnal Pendidikan IPA, 7 (2), 190-198.

Harja, M. (2012). Pemahaman konsep dalam pembelajaran matematika dengan pendekatan konstruktivisme. Jurnal Pendidikan, 1(1), 1-8.

Hasan, S., Diola B., \& Kelley E. L. (1999). Misconseption and the certainty of response index (CRI). Physics Education, 34 (5), 294-302.

Herlinah. (2014). Pengaruh penggunaan multimedia interaktif terhadap minat belajar mahasiswa pada STMIK Handayani Makasar. Jurnal Penelitian Komunikasi dan Opini Publik, 18 (3): 241-250.

Huda, A., A. (2013). Live Coding! 9 Aplikasi Buatan Sendiri. Yogyakarta: ANDI.

Ibrahim, M. (2000). Pembelajaran Kooperatif. University Press: Surabaya.

Mauke, M., Sadia I. W., \& Suastra I. W. (2013). Pengaruh model contextual teaching and learning terhadap pemahaman konsep dan kemampuan pemecahan masalah dalam pembelajaran IPA-Fisika di MTs Negeri Negara. e- Journal Program Pascasarjana Universitas Pendidikan Ganesha, 3 (2), 1-11.

Meilana, J. R. (2017). Pengembangan modul mobile learning berbasis android pada materi fluida statis. Jurnal Pembelajaran Fisika, 5 (5): 4-15. 
Meltzer, D. E. (2002). The relationship between matemathics preparation and conceptual learning gains in physics: A possible: Hidden variable in diagnostic pretest score. American Journal Physics, 70 (2), 1259-1268.

Mulyasa, E. (2003). Kurikulum Berbasis Kompetensi: Konsep, Karakteristik, dan Implementasi. Bandung: Remaja Rosdakarya.

Murtiwijayati dan Glenn L. (2013). Rancang bangun aplikasi pembelajaran budaya indonesia untuk anak sekolah dasar berbasis android. Jurnal Ilmiah Komputasi, 12 (2), 3-11.

Nasution. (2011). Berbagai Pendekatan dalam Proses Belajar Mengajar. Jakarta: Bumi Aksara.

OECD. (2018). Pisa 2015 Results in Fokus. https://www.oecd.org/ pisa/.

Parmin \& Peniati E. (2012). Pengembangan modul mata kuliah strategi belajar mengajar IPA berbasis hasil penelitian pembelajaran. Jurnal Pendidikan IPA Indonesia, 1 (1), 1-9.

Prastowo, A. (2012). Panduan Kreatif Membuat Bahan Ajar Inovatif. Yogyakarta: Diva Press.

Purwantoro, Sugeng, Rahmawati, H., \& Tharmizi, A. (2013). Mobile searching objek wisata pekanbaru menggunakan location base service (LBS) berbasis android. Jurnal Politeknik Caltex Riau, 1 (14), 176-184.

Radityan, R. S., Iwa K., \& Mumu K. (2014). Pengaruh multimedia interaktif terhadap hasil belajar siswa pada kompetensi perbaikan differential. Journal of Mechanical Engineering Education, 1 (2), 239-247.

Sakdiah, Mursal, \& Muhammad S. (2018). Penerapan model inkuiri terbimbing untuk meningkatkan pemahaman konsep siswa. Jurnal IPA dan Pembelajaran IPA (JIPI), 2 (1), 41-49.

Sanjaya, W. (2012). Strategi Pembelajaran Berorientasi Standar Proses Pendidikan. Jakarta: Kencana Prenada Media Group.

Sardiman, A.M. (2004). Interaksi dan Motivasi Belajar Mengajar. Jakarta: PT. Raja Grapindo Persada.

Setiawan, M. A., Dewa, I. W., \& Siti, M. (2016). Pengaruh bahan ajar multimedia terhadap hasil belajar. Jurnal Pendidikan, 1 (4): 746-754.

Simamora, F. G. (2017). Pengaruh penggunaan modul pembelajaran berbasis LCDS terhadap hasil belajar siswa. Jurnal Pembelajaran Fisika, 5 (3), 4-15.

Sismadiyanto, Kriswanto, E. S., Muktiani, N. R., \& Hastuti, T. A. (2008). Pengembangan multimedia interaktif untuk pembelajaran mata kuliah pendidikan kesehatan sekolah bagi mahasiswa prodi PJKR FIK UNY. Jurnal Pendidikan Jasmani Indonesia, 5 (2), 74-82.

Sudarsono. (2004). Media Pembelajaran sebagai Pilihan dalam Strategi Pembelajaran. Jakarta: Prenada Media.

Suryaningsih. (2010). Pengembangan Media Cetak Modul Sebagai Media Pembelajaran Mandiri. Jakarta: Salemba Empat.

Suryosubroto. (2002). Proses Belajar Mengajar di Sekolah. Jakarta: Rineka Cipta.

Susilo, A., Sunarno, W., \& Sukarmin. (2018). Pembelajaran fisika menggunakan metode inkuiri terbimbing dan inkuiri bebas termodifikasi berdasarkan kompendium Alqur'an ditinjau dari kedisiplinan belajar dan sikap ilmiah. Jurnal Pendidikan IPA, 7 (2), 160-168.

Suyanto, M. (2005). Multimedia Alat untuk Meningkatkan Keunggulan Bersaing. Yogyakarta: Andi.

Syamsidar, S. (2018). Pembelajaran fisika berbasis cone of experience Edgar Dale pada materi elastisitas dan fluida statis. Jurnal Pendidikan Fisika, 6 (1), 4-14. 
Formatif: Jurnal Ilmiah Pendidikan MIPA

Vol. 9, No. 4, December 2019, pp. 305-314

p-ISSN: 2088-351X

e-ISSN: 2502-5457

DOI: http://dx.doi.org/10.30998/formatif.v9i4.3530

Trianto. (2011). Mendesain Model Pembelajaran Inovatif-Progresif: Konsep, Landasan, dan Implementasinya pada Kurikulum Tingkat Satuan Pendidikan. Jakarta: Kencana.

Waluya, B. (2008). Penggunaan model pembelajaran generatif untuk meningkatkan pemahaman siswa. Jurnal Pendidikan UPI, 2 (1), 9-18.

Winkel. (2009). Psikologi Pengajaran. Yogyakarta : Media Abadi.

Zuliana \& Padli, I. (2013). Aplikasi pusat panggilan tindakan kriminal di kota Medan berbasis android. Jurnal IAIN Sumatera Utara Medan, 1 (2), 2-4. 